\title{
Contribution of Irradiation and Dihydroxybenzenes on Iron(III) Reduction in Fenton Process
}

\author{
Beatriz Costa e Silva and Raquel F. P. Nogueira* \\ Departamento de Química Analítica, Instituto de Química, Universidade Estadual Paulista \\ "Júlio de Mesquita Filho" (UNESP), CP 355, 14801-970 Araraquara-SP, Brazil
}

\begin{abstract}
The contribution of irradiation and the dihydroxybenzenes (DHB), catechol (CAT) and hydroquinone (HQ), added or formed as phenol oxidation intermediates, was evaluated for the reduction of $\mathrm{Fe}^{\mathrm{III}}$ and for phenol degradation via Fenton processes. The formation of CAT and HQ was observed during phenol degradation starting with $\mathrm{Fe}^{2+}$ or $\mathrm{Fe}^{3+}$ in the presence or absence of irradiation and their presence increased the rate of phenol degradation, more remarkably when initially added. Initial phenol degradation rate in the presence of DHB in the dark was much higher in comparison to their absence due to the initial higher and faster formation of $\mathrm{Fe}^{2+}$. However, degradation slows down due to the rapid oxidation of DHB, while under irradiation of free iron or citrate complex much higher mineralization is achieved in shorter time.
\end{abstract}

Keywords: catechol, hydroquinone, complex, phenol

\section{Introduction}

One of the most promising advanced oxidation processes (AOPs) for treatment of effluents containing recalcitrant contaminants is that based on Fenton reaction. They are carried out during the decomposition of $\mathrm{H}_{2} \mathrm{O}_{2}$ with free, complexed or insoluble $\mathrm{Fe}^{\mathrm{II}}$ species, due mainly to the fast generation of highly oxidizing and non selective species, hydroxyl radical $\left(\bullet \mathrm{OH} ; \mathrm{E}^{0}=2.8 \mathrm{~V}\right.$, vs. normal hydrogen electrode) which may promote the oxidation of a variety of organic contaminants. Other important advantages are the relatively low cost of the reagents involved, the mild operation conditions employed, absence of iron toxicity and the environmentally benign character of $\mathrm{H}_{2} \mathrm{O}_{2}$ at the concentrations used. ${ }^{1,2}$ Despite the high oxidation power of the process, an important limiting step is the regeneration of $\mathrm{Fe}^{\mathrm{II}}$ in the catalytic $\mathrm{Fe}^{\mathrm{II}} / \mathrm{Fe}^{\mathrm{III}}$ cycle, due to the quick oxidation of $\mathrm{Fe}^{\mathrm{II}}$ to $\mathrm{Fe}^{\mathrm{III}}$, which accumulates in solution due to the much slower reaction between $\mathrm{Fe}^{\text {III }}$ and $\mathrm{H}_{2} \mathrm{O}_{2}$ (equations 1 and 2), decreasing considerably the rate of $\bullet \mathrm{OH}$ generation.

$$
\begin{array}{ll}
\mathrm{Fe}^{\mathrm{II}}+\mathrm{H}_{2} \mathrm{O}_{2} \rightarrow \mathrm{Fe}^{\mathrm{III}}+\mathrm{HO} \bullet+\mathrm{HO}^{-} & \mathrm{k}=76 \mathrm{M}^{-1} \mathrm{~s}^{-1} \\
\mathrm{Fe}^{\mathrm{III}}+\mathrm{H}_{2} \mathrm{O}_{2} \rightarrow \mathrm{Fe}^{\mathrm{II}}+\mathrm{HO}_{2}^{+}+\mathrm{H}^{+} & \mathrm{k}=0.01 \mathrm{M}^{-1} \mathrm{~s}^{-1}
\end{array}
$$

High concentrations of $\mathrm{Fe}^{\mathrm{II}}$ increase the rate of oxidation process, however catalytic amounts of $\mathrm{Fe}^{\mathrm{II}}$ or $\mathrm{Fe}^{\mathrm{III}}$ are preferred to avoid the formation of $\mathrm{Fe}^{\mathrm{III}}$ hydroxides sludge. Therefore, the degradation efficiency of organic contaminants are strongly dependent on reduction of $\mathrm{Fe}^{\mathrm{III}}$ species, which can be overcome by the use of radiation (photo-Fenton process), increasing drastically the efficiency of the overall process through the photolysis of $\mathrm{Fe}^{\mathrm{III}}$ species, such as aqua and some organic complexes, which dissociate in the excited state to yield $\mathrm{Fe}^{\mathrm{II}}$ and oxidized ligand. . $^{1,3,4}$ Photolysis of ferric complexes with organic ligands as oxalate, citrate or tartrate greatly enhances $\mathrm{Fe}^{\mathrm{III}}$ reduction rates due to an effective ligand to metal charge transfer and by the shift of absorption toward longer wavelengths in relation to the aqua complexes..$^{5-8}$

In the dark, reduction rates of $\mathrm{Fe}^{\mathrm{III}}$ species depend on the redox potential of the reaction medium, but can be also significantly affected by the presence of reducing organic species. Orto- and para-dihydroxybenzene (DHB) compounds, such as catechol (CAT) and hydroquinone (HQ), have capacity to reduce iron(III) ${ }^{9-11}$ as can other phenol derivatives. ${ }^{12}$ Considering that one of the first steps in the degradation of aromatic compounds is the benzenic ring hydroxylation due to electrophilic addition of hydroxyl radical, the generation of di and trihydroxylated intermediates may occur and contribute to the reduction of $\mathrm{Fe}^{\mathrm{III}}$ species. ${ }^{9,13,14}$

*e-mail: nogueira@iq.unesp.br 
It has been proposed that CAT and HQ are oxidized to the respective semiquinones (SQ•) in a one-step electron transfer, reducing $\mathrm{Fe}^{\mathrm{III}}$ to $\mathrm{Fe}^{\mathrm{II}}$; in a second step, $\mathrm{SQ} \bullet$ is oxidized to quinone either by another $\mathrm{Fe}^{\mathrm{III}}$ or $\mathrm{O}_{2}$, which can also act as the electron acceptor, and be reduced by the semiquinone radical to superoxide/hydroperoxide radicals, $\mathrm{O}_{2}{ }^{-} / \mathrm{HO}_{2}{ }^{*}$, that can be converted to $\mathrm{H}_{2} \mathrm{O}_{2} \cdot{ }^{9}, 10,15,16$

Considering these two main iron reduction mechanisms, the objective of this study was to compare the contribution of DHB, added or formed as phenol degradation products, on reduction of $\mathrm{Fe}^{\mathrm{III}}$ in the dark and under irradiation (photoreduction) in the presence and absence of citrate as iron complexing agent, using identical reaction conditions (initial $\mathrm{pH}, \mathrm{Fe}^{\mathrm{III}}, \mathrm{H}_{2} \mathrm{O}_{2}$ and phenol concentration).

\section{Experimental}

\section{Reagents}

Phenol (Vetec, Rio de Janeiro, RJ, Brazil) was used to prepare aqueous solution of $40 \mathrm{mg} \mathrm{L}^{-1}$. $\mathrm{Fe}\left(\mathrm{NO}_{3}\right)_{3} 9 \mathrm{H}_{2} \mathrm{O}$ (J. T. Baker, Tokyo, Japan) and $\mathrm{FeSO}_{4} 7 \mathrm{H}_{2} \mathrm{O}$ (F. Maia, Cotia, SP, Brazil) were used to prepare aqueous iron stock solution of $0.25 \mathrm{~mol} \mathrm{~L}^{-1}$. Citric acid (Synth, Diadema, SP, Brazil) was used as iron ligand. Hydroquinone from CAAL (São Paulo, SP, Brazil) and catechol from SigmaAldrich (St. Louis, MO, USA) were used. $\mathrm{H}_{2} \mathrm{O}_{2}(30 \%, \mathrm{~m} / \mathrm{m}$; Synth, Diadema, SP, Brazil) was used as received after standardization. Bovine liver catalase from Sigma-Aldrich (St. Louis, MO, USA) was used for residual hydrogen peroxide consumption. Ammonium metavanadate (Vetec, Rio de Janeiro, RJ, Brazil) $0.06 \mathrm{~mol} \mathrm{~L}^{-1}$ was prepared in $0.36 \mathrm{~mol} \mathrm{~L}^{-1} \mathrm{H}_{2} \mathrm{SO}_{4}$ (Merck \& Co., Inc., Kenilworth, NJ, USA) and used for hydrogen peroxide determination. Methanol (J. T. Baker, Tokyo, Japan), acetic acid (Vetec, Rio de Janeiro, RJ, Brazil) and ultrapure water (Gehaka, São Paulo, SP, Brazil) were used for high-performance liquid chromatography (HPLC) analysis.

\section{Degradation procedures}

Experiments under irradiation and in the dark were carried out in an up flow reactor previously described. ${ }^{17}$ The irradiation source was a $15 \mathrm{~W}$ black-light lamp with maximum emission at 365 and $410 \mathrm{~nm}$. When irradiation was employed, the lamp was only switched on once the reactor was completely filled and the time started to be monitored. Experiments in the dark were performed in the same reactor but with the lamp switched off. The $\mathrm{pH}$ of the solution was then adjusted to 2.5 with addition of $1 \mathrm{~mol} \mathrm{~L}^{-1} \mathrm{H}_{2} \mathrm{SO}_{4}$ solution, $\mathrm{pH}$ in the optimum range of
photo-Fenton process. ${ }^{17,18}$ After $\mathrm{pH}$ adjustment, the iron salt was added to result in $0.10 \mathrm{mmol} \mathrm{L}-1$ concentration. Iron citrate complex (Fecit) was prepared in situ by the addition of citric acid to iron nitrate solution at 1:1 iron to ligand molar ratio. Appropriate volume of $\mathrm{H}_{2} \mathrm{O}_{2}$ was then added to result in $2.5 \mathrm{mmol} \mathrm{L}^{-1}$ solution while magnetically stirred, and the solution was immediately pumped into the reactor. The irradiated volume of the reactor was $280 \mathrm{~mL}$ and the total volume $500 \mathrm{~mL}$. Phenol solution $\left(40 \mathrm{mg} \mathrm{L}^{-1}\right.$; $0.42 \mathrm{mmol} \mathrm{L}^{-1}$ ) was recirculated at $80 \mathrm{~mL} \mathrm{~min}^{-1}$ flow rate, using a peristaltic pump (Masterflex 7518-12, Cole-Parmer Instrument Co. Ltd., London, UK). These concentrations of phenol, iron and $\mathrm{H}_{2} \mathrm{O}_{2}$ were chosen after preliminary tests to enable the detection and quantification of CAT and HQ, besides of phenol. Catechol and HQ were added at concentrations ranging from 0 to $1.50 \mathrm{mmol} \mathrm{L}^{-1}$ to evaluate their effect on iron reduction and on phenol degradation.

\section{Chemical analysis}

The concentration of phenol, CAT and HQ during the experiments was determined using reversed-phase HPLC (LC-20AT Prominence, Shimadzu, Kyoto, Japan) coupled to a diode array detector (DAD) SPD-M20A. The injection volume was $40 \mu \mathrm{L}$ and a Gemini $5 \mathrm{~mm} \mathrm{C} 18$ column $(150 \times 4.6 \mathrm{~mm}$; Phenomenex, Torrance, CA, USA $)$ was used with a mixture of methanol:acetic acid 1.0\% (25:75, v/v) as mobile phase at $1.0 \mathrm{~mL} \mathrm{~min}^{-1}$ flow rate. Under these conditions, retention time of phenol, CAT and HQ were 8.3, 4.6 and 2.6 min detected at 270, 276 and $289 \mathrm{~nm}$ wavelength, respectively. Before HPLC analysis, $35 \mu \mathrm{L}$ of catalase solution $\left(0.1 \mathrm{~g} \mathrm{~L}^{-1}\right)$ were added to $5 \mathrm{~mL}$ aqueous sample after $\mathrm{pH}$ adjustment to 6-7. This procedure was adopted to interrupt the Fenton reaction by the decomposition of residual $\mathrm{H}_{2} \mathrm{O}_{2}$ and iron precipitation. ${ }^{19}$ The samples were then filtered through $0.45 \mu \mathrm{m}$ polyvinylidene fluoride (PVDF) membrane (Millipore, Billerica, MA, USA) before HPLC analysis.

Mineralization of organic matter during phenol degradation was evaluated by measuring the decay of the total organic carbon concentration (TOC) using a TOC analyzer (TOC-5000A, Shimadzu, Kyoto, Japan). TOC was measured immediately after the sample withdrawal without previous treatment.

The residual hydrogen peroxide concentration was determined spectrophotometrically (UV Mini 1240, Shimadzu, Kyoto, Japan) by measuring the absorption at $450 \mathrm{~nm}$ after reaction with ammonium metavanadate. ${ }^{20}$ The concentration of ferrous ions generated during the degradation experiments was measured using the spectrophotometric method employing 1,10-phenanthroline, with maximum absorption at $510 \mathrm{~nm}^{21}$ 


\section{Results and Discussion}

Phenol was used as a model compound to verify the effect of dihydroxybenzenes on degradation rate, since it has been previously observed that CAT and HQ are two isomers formed as initial products as a consequence of hydroxyl radical attack to benzenic ring. ${ }^{9,22}$ Control experiments under only irradiation or in the presence of only $\mathrm{H}_{2} \mathrm{O}_{2}, \mathrm{Fe}^{2+}$ or $\mathrm{Fe}^{3+}$ showed no decrease of phenol concentration. However, irradiation in the presence of $\mathrm{Fe}^{2+}$ resulted in $10 \%$ phenol oxidation with no mineralization after $90 \mathrm{~min}$.

Phenol degradation in the dark in the presence of $\mathrm{Fe}^{2+}$ and $\mathrm{H}_{2} \mathrm{O}_{2}$ started with a low rate resulting in a phenol decrease of only $0.8 \mathrm{mg} \mathrm{L}^{-1} \mathrm{~min}^{-1}$ in the first $10 \mathrm{~min}$, while the degradation rate increased about 3 times, reaching $2.5 \mathrm{mg} \mathrm{L}^{-1} \mathrm{~min}^{-1}$ degradation after $15 \mathrm{~min}$ of reaction. Similar behavior was observed under irradiation, however with higher initial rate due to the contribution of irradiation on $\mathrm{Fe}^{2+}$ regeneration, achieving $1.4 \mathrm{mg} \mathrm{L}^{-1} \mathrm{~min}^{-1}$ after $7 \mathrm{~min}$ and $3.1 \mathrm{mg} \mathrm{L}^{-1} \mathrm{~min}^{-1}$ after $15 \mathrm{~min}$. In both cases, over $98 \%$ phenol degradation was observed after $30 \mathrm{~min}$ in the dark and under irradiation (Figure 1a).

Phenol degradation in the presence of $\mathrm{Fe}^{3+}$ and $\mathrm{H}_{2} \mathrm{O}_{2}$ under irradiation started also with a low rate up to $13 \mathrm{~min}$, achieving a removal rate of only $0.7 \mathrm{mg} \mathrm{L}^{-1} \mathrm{~min}^{-1}$, while it was accelerated achieving $3.8 \mathrm{mg} \mathrm{L}^{-1} \mathrm{~min}^{-1}$ up to $20 \mathrm{~min}$. However, in the dark, no phenol degradation occurred due to the much lower rate of $\mathrm{H}_{2} \mathrm{O}_{2}$ decomposition with $\mathrm{Fe}^{3+}$ in comparison to $\mathrm{Fe}^{2+}$. Similar behavior was previously observed during the same experimental time, but starting with $2 \mathrm{mmol} \mathrm{L}^{-1}$ phenol. ${ }^{9}$

In relation to TOC removal, a different behavior was observed. Since in the absence of irradiation using $\mathrm{Fe}^{2+}, 16 \%$ removal was achieved after 90 min due to total conversion of $\mathrm{Fe}^{2+}$ to $\mathrm{Fe}^{3+}$. On the other hand, the TOC removal under irradiation achieved 76 and $60 \%$ of mineralization after 90 min with $\mathrm{Fe}^{2+}$ and $\mathrm{Fe}^{3+}$, respectively (Figure $1 \mathrm{~b}$ ).

The $\mathrm{H}_{2} \mathrm{O}_{2}$ consumption presented similar behavior when compared to phenol oxidation (Figure 1c). However, the consumption of $\mathrm{H}_{2} \mathrm{O}_{2}$ (mols of $\mathrm{H}_{2} \mathrm{O}_{2}$ consumed per mols of phenol oxidized) when $\mathrm{Fe}^{2+}$ was used under irradiation was slightly higher than in the dark: 5.0 after $20 \mathrm{~min}$, while it was 4.3 in the dark. This indicates that under irradiation part of $\mathrm{H}_{2} \mathrm{O}_{2}$ was thermally decomposed without generation of hydroxyl radical, since mineralization was very similar up to $10 \mathrm{~min}$.

During phenol degradation, both CAT and HQ were monitored to investigate if their generation in solution could be correlated with the change in the reaction rate of phenol degradation observed (Figure 1a). HQ was first detected after $5 \mathrm{~min}$, achieving a maximum concentration $\left(0.0045 \mathrm{mmol} \mathrm{L}^{-1}\right)$ after 7 min when $\mathrm{Fe}^{2+}$ was used in the dark, while CAT achieved $0.015 \mathrm{mmol} \mathrm{L}^{-1}$ after $10 \mathrm{~min}$ (Figure 1d). This concentration of CAT corresponds to approximately $4 \%$ phenol conversion. In the presence of irradiation, CAT was detected after 3 min achieving a maximum concentration after $7 \mathrm{~min}\left(0.0077 \mathrm{mmol} \mathrm{L}^{-1}\right)$ and after $10 \mathrm{~min}$ HQ was detected, achieving 0.0027 after $13 \mathrm{~min}$. It is important to mention that these are the measured concentrations and both CAT and HQ can be formed and degraded continuously.

When $\mathrm{Fe}^{3+}$ was used under irradiation, only HQ was detected, achieving $0.0027 \mathrm{mmol} \mathrm{L}^{-1}$ after $20 \mathrm{~min}$ and increasing phenol degradation up to $30 \mathrm{~min}$, when HQ started to be degraded. It can be observed that after the maximum concentration of CAT and HQ were achieved, the rate of phenol degradation was increased, which suggests that the DHB formed strongly influenced phenol degradation rate, probably by the regeneration of $\mathrm{Fe}^{2+}$ (Figure 1a). The process was slower with $\mathrm{Fe}^{3+}$ since it must be firstly reduced by irradiation for further reaction with $\mathrm{H}_{2} \mathrm{O}_{2}$, which delayed hydroquinone formation occurring only after $20 \mathrm{~min}$ (Figure 1d).

Considering that the detection of CAT and HQ during phenol degradation indicated their influence in the increase of phenol degradation rate, the effect of addition of these compounds to phenol solution in the beginning of reaction was evaluated at concentrations ranging from 0.05 to $1.50 \mathrm{mmol} \mathrm{L}^{-1}$.

After addition of CAT or HQ to phenol solution, other peaks were detected in chromatographic analysis carried out immediately after DHB addition, with retention times $\left(\mathrm{t}_{\mathrm{r}}\right)$ of 3.4 and $3.7 \mathrm{~min}$, respectively. It was also observed that the area of these peaks increased with increasing concentration of $\mathrm{Fe}^{3+}$ (Figures 2a and 2b, indicated by an arrow) and that the area of CAT $\left(\mathrm{t}_{\mathrm{r}}=4.5 \mathrm{~min}\right)$ and HQ $\left(\mathrm{t}_{\mathrm{r}}=2.6 \mathrm{~min}\right)$ peak decreased in relation to the concentration initially added to the solution (Figures 2a and 2b). The ultraviolet visible (UV-Vis) absorption spectra of the solutions of CAT and HQ with increasing concentrations of $\mathrm{Fe}^{3+}$ were registered and showed an increase of absorption at 386 and $246 \mathrm{~nm}$, respectively, suggesting the oxidation of DHB to the corresponding quinones in the dark and absence of $\mathrm{H}_{2} \mathrm{O}_{2}$, since the absorption spectrum of 1,2-benzoquinone and 1,4-benzoquinone have a maximum wavelength at 385 and $248 \mathrm{~nm}$, respectively. ${ }^{23}$ On the other hand, absorbance at the characteristic absorptions of CAT $(276 \mathrm{~nm})$ and HQ $(289 \mathrm{~nm})$ decrease slightly (Figures $2 \mathrm{c}$ and 2d), indicating a decrease of CAT and HQ concentrations, which is in accordance with the decrease of the corresponding area in chromatograms. 

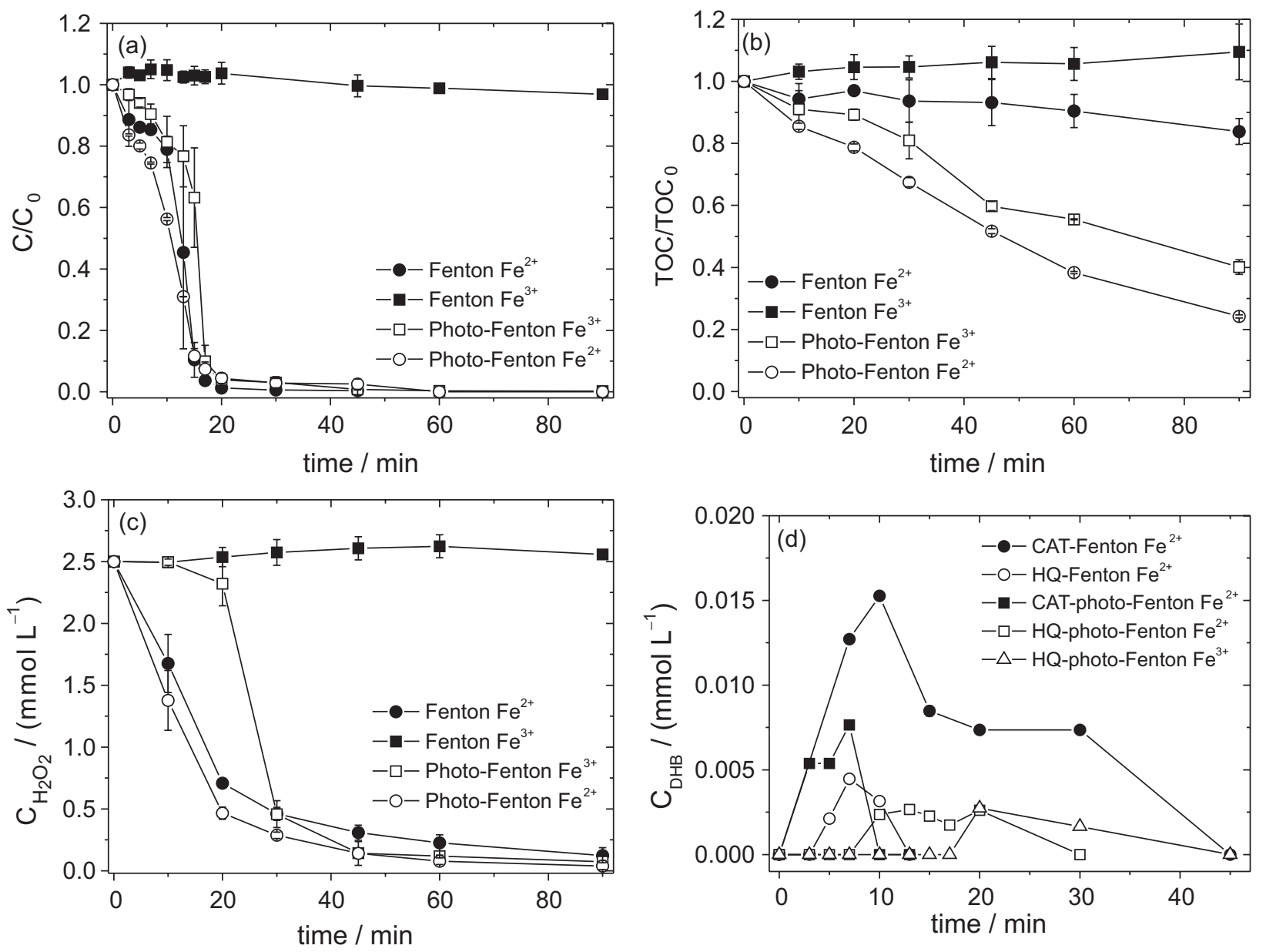

Figure 1. Influence of irradiation and iron species on phenol oxidation (a); mineralization (b); $\mathrm{H}_{2} \mathrm{O}_{2}$ consumption (c); and catechol (CAT) and hydroquinone (HQ) formed (d) in the dark or under irradiation. Initial conditions: $\mathrm{C}_{\text {phenol }}=40 \mathrm{mg} \mathrm{L}^{-1}, \mathrm{C}_{\mathrm{Fe}}=0.1 \mathrm{mmol} \mathrm{L}^{-1}, \mathrm{C}_{\mathrm{H}_{2} \mathrm{O}_{2}}=2.5 \mathrm{mmol} \mathrm{L}^{-1}$, $\mathrm{pH} 2.5$. Error bars of triplicate experiments are shown.

When catechol and hydroquinone were initially added to phenol solution in the presence of $\mathrm{Fe}^{3+}$, phenol degradation followed a first order kinetics and the rate constants were calculated for the different initial concentrations of the DHB (Table 1). The addition of $0.05,0.10$ and $0.15 \mathrm{mmol} \mathrm{L}^{-1}$ increased the initial oxidation rate of phenol independently of the concentration added. The addition of HQ and CAT resulted in more than $95 \%$ phenol oxidation after 13 and $20 \mathrm{~min}$, respectively. In relation to mineralization, very similar results were observed in the presence of either CAT or HQ, about 10 to $15 \%$ TOC removal after 10 min, with no further mineralization, probably due to the total conversion of these compounds.

The Fecit complex was used as iron source to compare the efficiency of free and complexed iron in the reduction of $\mathrm{Fe}^{3+}$ and to verify if the complexed iron affected the formation of DHB. Phenol degradation in the presence of Fecit and irradiation started with a low rate up to $7 \mathrm{~min}$, achieving $0.8 \mathrm{mg} \mathrm{L}^{-1} \mathrm{~min}^{-1}$ but achieving $2.3 \mathrm{mg} \mathrm{L}^{-1} \mathrm{~min}^{-1}$ up to $20 \mathrm{~min}$, higher oxidation rate than with free $\mathrm{Fe}^{\mathrm{III}}$, but lower than with added DHB (Figure 3a). The $\mathrm{H}_{2} \mathrm{O}_{2}$ consumption presented a behavior similar to the phenol oxidation (Figure 3c). Organic compounds degradation in the presence of citrate under irradiation at $\mathrm{pH} 2.5 \pm 0.2$ may be attributed to the formation of complexes such as $\mathrm{Fe}^{\mathrm{III}}$-citrate and $\mathrm{Fe}^{\mathrm{III}} \mathrm{H}$-citrate, which represent about 80 and $5 \%$ of the total iron species, respectively (calculated by Visual Minteq 3.1 software) ${ }^{24}$ In the presence of citrate, $\mathrm{Fe}^{\mathrm{III}}$ is reduced under irradiation due to a ligand to metal charge transfer, exhibiting higher photoactivity to produce - $\mathrm{OH}$ under irradiation than in the absence of citrate..$^{25}$

In the presence of citrate, CAT was formed only after $20 \mathrm{~min}$, achieving $0.25 \mathrm{mmol} \mathrm{L}^{-1}$, indicating that the formation of CAT started after partial degradation of citrate, as can be observed by TOC concentration (Figure 3).

$\mathrm{Fe}^{2+}$ was determined during phenol degradation to compare the reduction of $\mathrm{Fe}^{3+}$ by $\mathrm{CAT}, \mathrm{HQ}$, citrate and irradiation in the absence of $\mathrm{H}_{2} \mathrm{O}_{2}$ to avoid $\mathrm{Fe}^{2+}$ oxidation (Figure 4). $\mathrm{Fe}^{\mathrm{III}}$ initially present was completely and immediately reduced after the addition of DHB, forming 

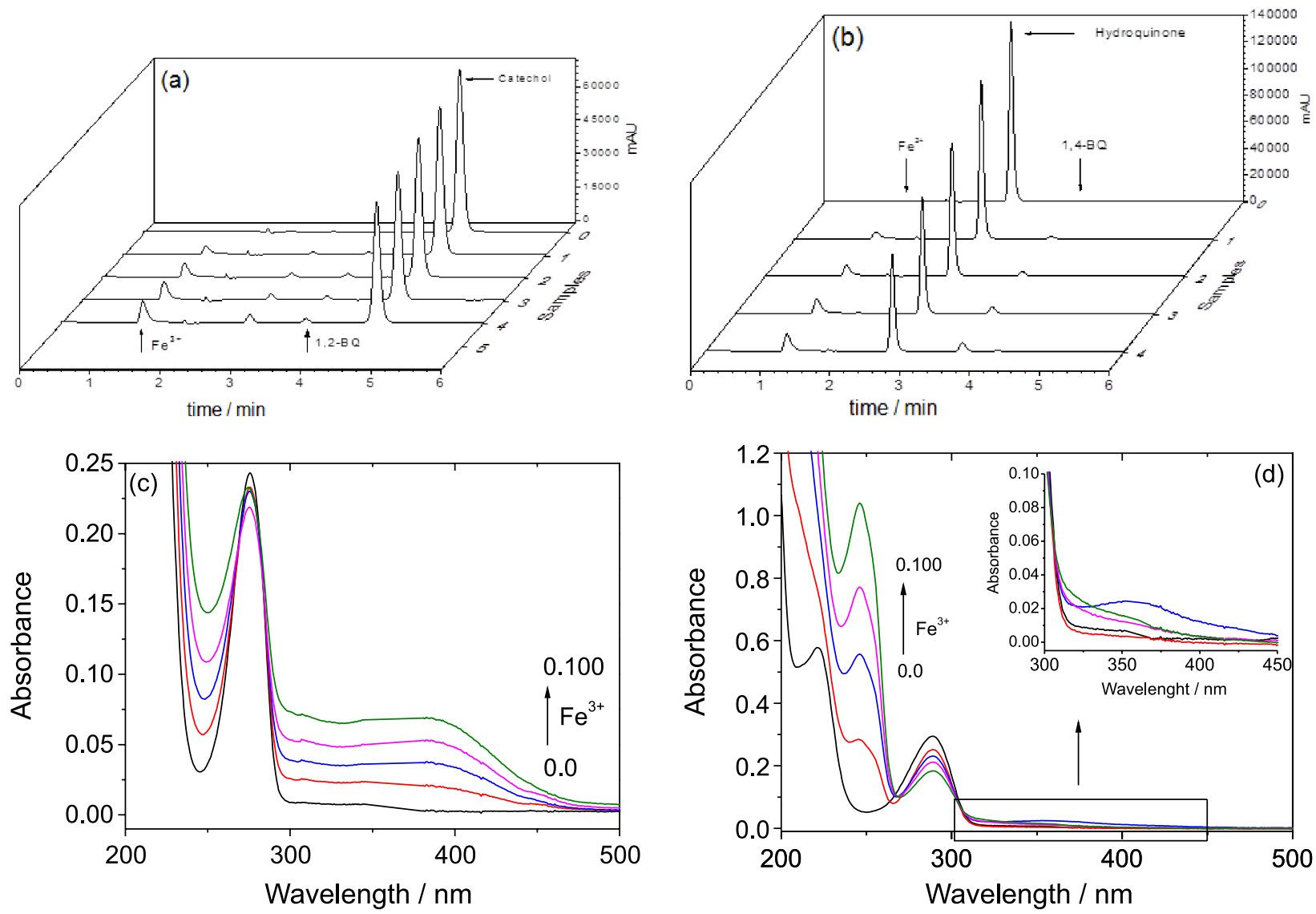

Figure 2. Chromatograms of catechol (CAT) $0.1 \mathrm{mmol} \mathrm{L}^{-1}$ (a) and hydroquinone (HQ) $0.1 \mathrm{mmol} \mathrm{L}^{-1}$ (b); and absorption spectra of CAT (c) and HQ (d) with increasing $\mathrm{Fe}^{3+}$ concentrations: 0, 0.025, 0.050, 0.075 and $0.100 \mathrm{mmol} \mathrm{L}^{-1}$, pH 2.5. 1,2-BQ: 1,2-benzoquinone; 1,4-BQ: 1,4-benzoquinone. Inset: approximation of spectra from 300 to $450 \mathrm{~nm}$.

Table 1. First order rate constant of phenol degradation in the dark in the presence of catechol (CAT) or hydroquinone (HQ)

\begin{tabular}{lcc}
\hline Dihydroxybenzene & $\begin{array}{c}\text { Concentration / } \\
\left(\mathrm{mmol} \mathrm{L}^{-1}\right)\end{array}$ & $\begin{array}{c}\text { Rate constant / } \\
\mathrm{min}^{-1}\end{array}$ \\
\hline \multirow{3}{*}{ CAT } & 0.05 & $0.18 \pm 0.10$ \\
& 0.10 & $0.32 \pm 0.04$ \\
& 0.15 & $0.31 \pm 0.02$ \\
\hline \multirow{2}{*}{ HQ } & 0.05 & $0.31 \pm 0.05$ \\
& 0.10 & $0.34 \pm 0.01$ \\
\hline
\end{tabular}

$\mathrm{C}_{\mathrm{Fe} 3+}=0.1 \mathrm{mmol} \mathrm{L}^{-1} ; \mathrm{C}_{\mathrm{H}_{2} \mathrm{O}_{2}}=2.5 \mathrm{mmol} \mathrm{L}^{-1} ; \mathrm{pH} 2.5(\mathrm{n}=3)$.

$\mathrm{Fe}^{2+}$ as previously observed. ${ }^{11,26}$ Irradiation of free iron and Fecit complex also lead to $\mathrm{Fe}^{\mathrm{III}}$ reduction, however at much lower rate. Irradiation of citrate complex resulted in higher rate of $\mathrm{Fe}^{2+}$ generation when compared to irradiation of free iron, but has reached a plateau, probably due to degradation of citrate and of CAT generated and, thus, reduction of $\mathrm{Fe}^{3+}$ ends. These results evidence the higher ability of HQ and CAT for the conversion of $\mathrm{Fe}^{3+}$ to $\mathrm{Fe}^{2+}$ in the dark when compared to irradiation of free and complexed iron, probably also due to the contribution of quinones formed on further $\mathrm{Fe}^{3+}$ reduction as previously observed. ${ }^{12}$

\section{Conclusions}

The results of this work indicate that phenol degradation is strongly affected by the presence of catechol or hydroquinone, since reaction kinetics changes drastically after their detection in the dark. Addition of these DHB in the beginning of reaction accelerated significantly phenol degradation due to strong iron reducing capacity of these compounds, confirmed by the immediate detection of $\mathrm{Fe}^{2+}$ after addition of $\mathrm{Fe}\left(\mathrm{NO}_{3}\right)_{3}$ solutions, much higher than $\mathrm{Fe}^{2+}$ generated in the photolysis of Fecit complex and free iron. However, despite this fast oxidation of phenol to DHB and subsequent oxidation to quinones, the irradiation of free iron or Fecit complex lead to much more efficient TOC removal independent of DHB, indicating the importance of the continuous effect of irradiation both on iron reduction and on phenol mineralization. Although the addition of DHB is not feasible in a practical application to wastewater treatment by Fenton process, the presence of contaminants 

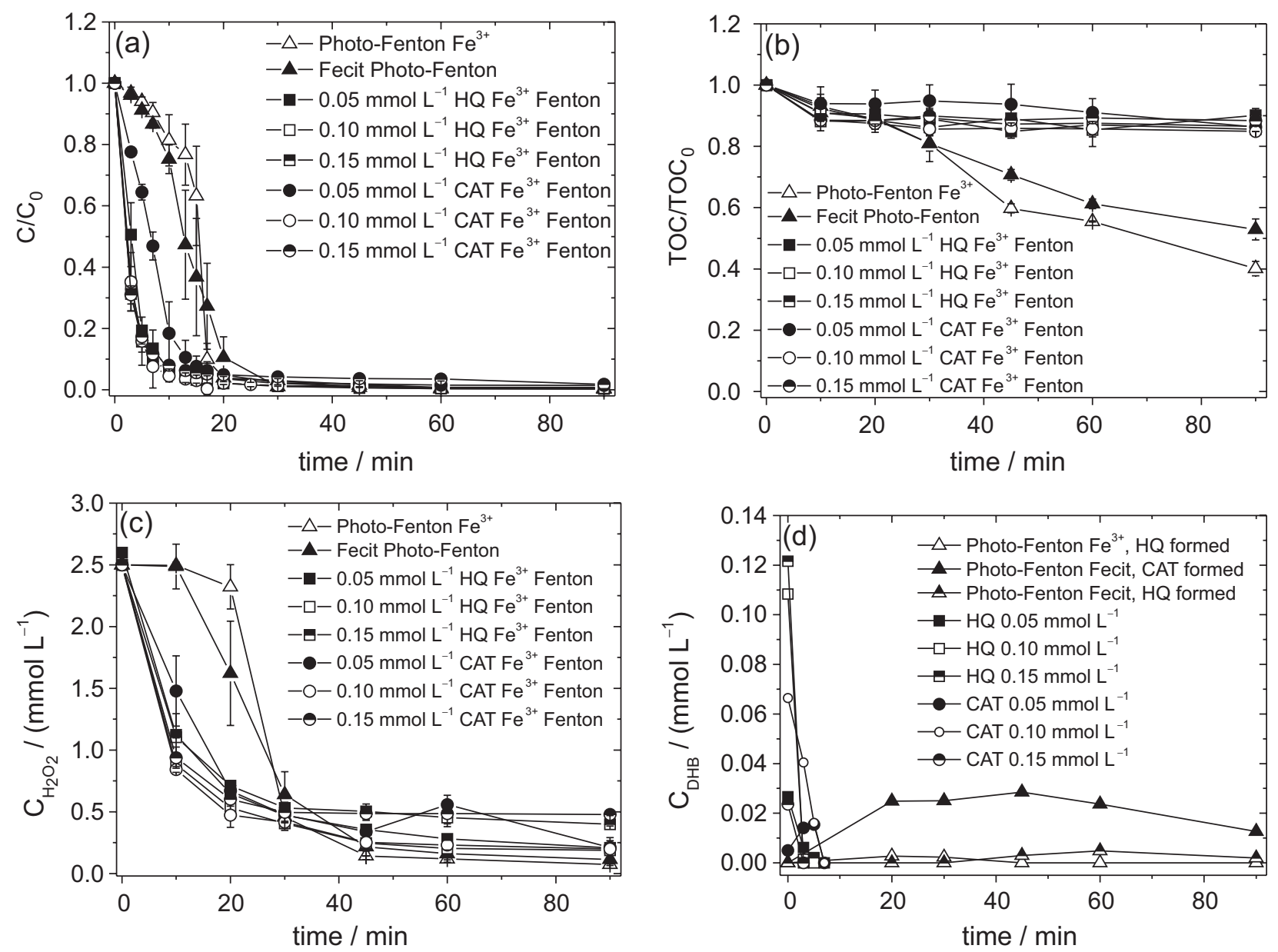

Figure 3. Influence of catechol (CAT) and hydroquinone (HQ) on oxidation (a); mineralization of phenol (b); $\mathrm{H}_{2} \mathrm{O}_{2}$ consumption (c); and dihydroxybenzenes (DHB) concentration (d). Initial conditions: $\mathrm{C}_{\text {phenol }}=40 \mathrm{mg} \mathrm{L}^{-1}, \mathrm{C}_{\mathrm{Fe}^{3+}}=0.1 \mathrm{mmol} \mathrm{L}^{-1}, \mathrm{C}_{\text {citric acid }}=0.1 \mathrm{mmol} \mathrm{L}^{-1}, \mathrm{C}_{\mathrm{H}_{2} \mathrm{O}_{2}}=2.5 \mathrm{mmol} \mathrm{L}-1, \mathrm{pH} 2.5$. Error bars of triplicate experiments are shown.

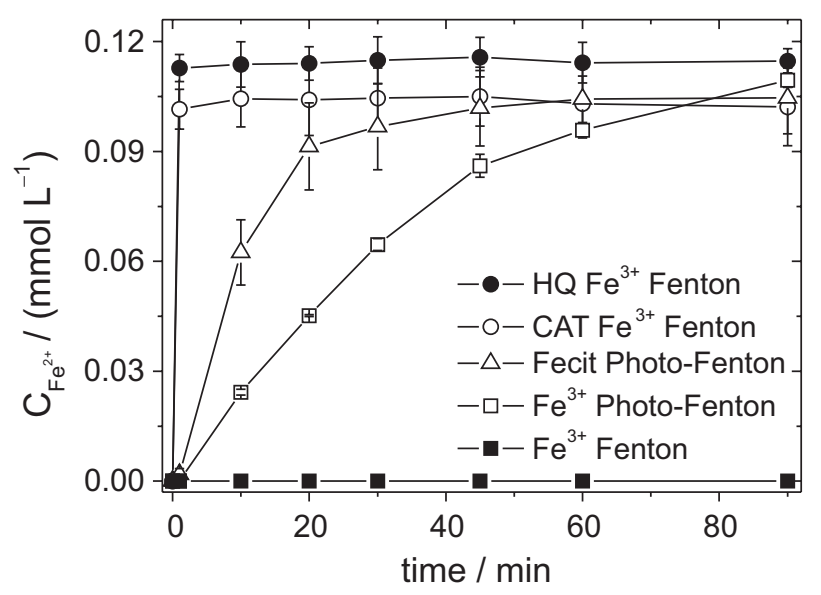

Figure 4. Generation of $\mathrm{Fe}^{\mathrm{II}}$ during phenol degradation under different conditions in the absence of $\mathrm{H}_{2} \mathrm{O}_{2}$. Error bars of triplicate experiments are shown. HQ: Hydroquinone; CAT: catechol.

with phenolic groups or other iron reducing organic compounds may strongly affect the initial degradation kinetics, favoring its application.

\section{Acknowledgments}

The authors thank CNPq for support of this work and CAPES for a scholarship awarded to B. Costa e Silva.

\section{References}

1. Legrini, O.; Oliveros, E.; Braun, A. M.; Chem. Rev. (Washington, DC, U. S.) 1993, 93, 671.

2. Pignatello, J. J.; Oliveros, E.; MacKay, A.; Crit. Rev. Environ. Sci. Technol. 2006, 36, 1.

3. Balzani, V.; Carassiti, V.; Photochemistry of Coordination of Compounds, $1^{\text {st }}$ ed.; Academic Press: London, 1970.

4. Faust, B. C.; Hoigne, J.; Atmos. Environ. 1990, 24, 79.

5. Abrahamson, H. B.; Rezvani, A. B.; Brushmiller, J. G.; Inorg. Chim. Acta 1994, 226, 117.

6. Wang, L.; Zhang, C.; Mestankova, H.; Wu, F.; Deng, N.; Pan, G.; Bolte, M.; Mailhot, G.; Photochem. Photobiol. Sci. 2009, 8, 1059. 
7. Safarzadeh-Amiri, A.; Bolton, J. R.; Cater, S. R.; Sol. Energy 1996, 56, 439.

8. Nogueira, R. F. P.; Silva, M. R. A.; Trovó, A. G.; Sol. Energy 2005, 79, 384.

9. Chen, R.; Pignatello, J. J.; Environ. Sci. Technol. 1997, 31, 2399.

10. Aguiar, A.; Ferraz, A.; Contreras, D.; Rodríguez, J.; Quim. Nova. 2007, 30, 623.

11. Du, Y.; Zhou, M.; Lei, L.; J. Hazard. Mater. 2006, B136, 859.

12. Aguiar, A.; Ferraz, A.; Chemosphere 2007, 66, 947.

13. Nichela, A. A.; Donadelli, J. A.; Caram, B. F.; Haddou, M.; Nieto, F. J. R.; Oliveros, E.; Einschlag, F. S. G.; Appl. Catal., B 2015, 170, 312 .

14. Devi, L. G.; Rajashekhar, K. E.; Raju, K. S. A.; Kumar, S. G.; Desalination 2011, 270, 31.

15. Contreras, D.; Rodríguez, J.; Freer, J.; Schwederski, B.; Kaim, W.; JBIC, J. Biol. Inorg. Chem. 2007, 12, 1055.

16. Chen, F.; Ma, W. H.; He, J. J.; Zhao, J. C.; J. Phys. Chem. A 2002, 106, 9485.

17. Nogueira, R. F. P.; Guimarães, J. R.; Water Res. 2000, 34, 895.

18. Pignatello, J. J.; Environ. Sci. Technol. 1992, 26, 944.
19. Malato, S.; Blanco, J.; Cáceres, J.; Fernandez-Alba A. R.; Agüera, A.; Rodriguez, A.; Catal. Today 2002, 76, 209.

20. Nogueira, R. F. P.; Oliveira, M. C.; Paterlini, W. C.; Talanta 2005, 66, 86 .

21. Fortune, W. B.; Mellon, M. G.; Ind. Eng. Chem., Anal. Ed. 1938, 10,60 .

22. Scheck, C. K.; Frimmel, F. H.; Water Res. 1995, 29, 2346.

23. http://srdata.nist.gov/gateway/gateway?substance=quinone $\& \mathrm{~s}$ ubft=Submit\&rddesc=desc accessed on December 2015.

24. Gustafsson, J. P.; Visual MINTEQ ver. 3.1; KTH Royal Institute of Technology, Sweden, 2014.

25. Guo, J.; Du, Y.; Lan, Y., Mao, J.; J. Hazard. Mater. 2011, 186, 2083.

26. Jiang, C.; Gao, Z.; Qu, H.; Li, J.; Wang, X.; Li, P.; Liu, H.; J. Hazard. Mater. 2013, 250, 76.

Submitted: September 16, 2015

Published online: January 25, 2016

FAPESP has sponsored the publication of this article. 